\title{
Spatio-temporal changes in annual accumulated temperature in China and the effects on cropping systems, 1980s to 2000
}

\author{
Jinwei Dong ${ }^{1,2}$, Jiyuan Liu ${ }^{1, *}$, Fulu Tao ${ }^{1}$, Xinliang Xu' ${ }^{1}$, Junbang Wang ${ }^{1}$ \\ ${ }^{1}$ Institute of Geographic Sciences and Natural Resources Research, Chinese Academy of Sciences, Beijing 100101, China \\ ${ }^{2}$ Graduate University of Chinese Academy of Sciences, Beijing 100039, China
}

\begin{abstract}
Change in thermal conditions can substantially affect crop growth, cropping systems, agricultural production and land use. In the present study, we used annual accumulated temperatures $>10^{\circ} \mathrm{C}$ (AAT10) as an indicator to investigate the spatio-temporal changes in thermal conditions across China from the late 1980s to 2000, with a spatial resolution of $1 \times 1 \mathrm{~km}$. We also investigated the effects of the spatio-temporal changes on cultivated land use and cropping systems. We found that AAT10 has increased on a national scale since the late 1980s. Particularly, $3.16 \times 10^{5} \mathrm{~km}^{2}$ of land moved from the spring wheat zone (AAT10: 1600 to $3400^{\circ} \mathrm{C}$ ) to the winter wheat zone (AAT10: 3400 to $4500^{\circ} \mathrm{C}$ ). Changes in thermal conditions had large influences on cultivated land area and cropping systems. The areas of cultivated land have increased in regions with increasing AAT10, and the cropping rotation index has increased since the late 1980s. Single cropping was replaced by 3 crops in 2 years in many regions, and areas of winter wheat cultivation were shifted northward in some areas, such as in the eastern Inner Mongolia Autonomous Region and in western Liaoning and Jilin Provinces.
\end{abstract}

KEY WORDS: Agriculture $\cdot$ Accumulated temperature $\cdot$ Climate change $\cdot$ Cropping system $\cdot$ China . Cultivated land $\cdot$ Land-use change

\section{INTRODUCTION}

The annual mean surface air temperature in China has increased $1.1^{\circ} \mathrm{C}$ over the past $50 \mathrm{yr}$. This is higher than the global average or even than that of the Northern Hemisphere for the same period. Striking warming has occurred since the mid-1980s (Ding et al. 2006, 2007), particularly in northern China (Qin et al. 2005). Recent studies have attempted to indicate the effects of climate change on agriculture and food production in the past or future by concentrating on the relationship of crop yield with climate changes such as temperature and precipitation (Lobell \& Asner 2003, Tao et al. 2003, 2006, 2008a, Liu et al. 2004, Lobell et al. 2008). However, the relationship between climate change and agricultural production is complex. Climate change influences food production by affecting agroecological conditions (Feng \& Hu 2004, Schmidhuber \& Tubiello 2007). Climate change has had, and will have, significant effects on agriculture in China (Liu et al. 2004, Tao et al. 2006, 2008a,b). As a result, farming systems and land-use patterns have been changing under changing climatic conditions; therefore, more studies are needed to assess possible effects of climate change on agroecological conditions and agricultural land use in China.

As a fundamental element of the agroecological condition, cultivated land is likely to be vulnerable to climate change. Increased surface air temperature has improved the thermal conditions for agricultural production despite the negative effects such as drought. Improved natural conditions have made more land in northwestern and northeastern China (the agropastoral transition zone) cultivatable, and crop phenol- 
ogy has advanced (Tao et al. 2006). Although several studies have investigated the effects of climate change on the agricultural water cycle (e.g. Tao et al. 2003, 2005), crop phenology (e.g. Tao et al. 2006) and crop yield (e.g. Tao et al. 2008a,b), related studies investigating the response mechanisms of cultivated land to climate change and variability are limited.

Thermal conditions are crucial in regulating crop growth. Crops must accumulate a certain quantity of heat to complete the process of growth. The annual accumulated temperature $>10^{\circ} \mathrm{C}$ (AAT10) is an important indicator of thermal conditions in crop ecology (Qiu \& Lu 1980, Bai et al. 2008). AAT10 affects the choice of crop varieties, the crop calendar, cropping systems and crop patterns (Zheng et al. 2008). Former studies of the thermal distribution of cultivated land on a macroscale have focused on designating physical and climate regions as they relate to agriculture (Qiu 1992), with AAT10 as an important indicator in this work.

Accumulated temperature zones (ATZs) within a country refer to different regions that are divided according to AAT10 criteria (Yu et al. 1997). With climate warming, the area and distribution of ATZs have changed. Important research questions include how ATZs change spatially, whether changing ATZs affect traditional cropping systems, if (and how) land use has changed as possible responses to changes in thermal conditions, and whether ATZ changes have potential benefits for future agriculture. Based on the above considerations, the primary purpose of the present study was to assess the relationship between accumulated temperature change and cultivated land use in China from the late 1980s to 2000. We first designated ATZs in 3 periods using spatial meteorological datasets with a $1 \mathrm{~km} \times 1 \mathrm{~km}$ resolution. Then, we extracted information on spatial variation of cultivated land under ATZs during the 3 periods from spatial grid data on land use with a $1 \mathrm{~km} \times 1 \mathrm{~km}$ resolution. We further analyzed the possible effects of AAT10 changes on spatial cultivated land changes and on cropping systems according to principles of crop ecology. Finally, we examine the possible effects on agriculture production.

\section{DATA AND METHODS}

\subsection{Data}

\subsubsection{Cultivated land data}

We used 3 periods (see below, this paragraph) of cropland area data developed by the Chinese Academy of Sciences (Liu 1996); each grid contained infor- mation on the percent area of cultivated land. Landuse vector data were acquired first by interpretation of Landsat TM images through a computer-aided, interactive procedure guaranteeing classification consistency and accuracy (Liu et al. 2003, 2005). Then, the vector data and a vector fishnet with cells of $1 \mathrm{~km} \times$ $1 \mathrm{~km}$ were intersected, and the area percentage of cultivated land in a cell was calculated as the value of the cell. Finally, the vector data were converted into raster grids (Liu et al. 2005). The 3 time periods of cropland area data included: (1) the late 1980s (which were interpreted from Landsat TM images from 1986-1989), (2) the mid-1990s (using Landsat TM images from 1995-1996) and (3) 2000 (from Landsat TM images from 1999-2000). The data indicated that the total cropland in China increased by $2.79 \times 10^{6}$ ha from 1990-2000, with substantial spatial variations across the nation (Liu et al. 2005).

\subsubsection{Meteorological data}

We used meteorological data from 752 meteorological stations run by the China Meteorological Administration (locations shown in Fig. 1). AAT10 data were calculated with Matlab according to daily average air surface temperature data. AAT10 points were then interpolated into raster grids using thin-plate smoothing splines with ANUspline software (Hutchinson 2002); the method took into account elevation in the process of interpolation for the surface, and original elevation data, with a resolution of $90 \mathrm{~m} \times$ $90 \mathrm{~m}$, were adopted. The surface air temperature grid data had a resolution of $1 \mathrm{~km} \times 1 \mathrm{~km}$, and Albers projection was used to match the data of cultivated land.

AAT10 is the sum of daily mean temperatures $\geq$ to the minimum biology temperature (here $10^{\circ} \mathrm{C}$ ). It is called the active accumulated temperature and is calculated using the following formula:

$$
\operatorname{AAT} 10=\sum_{i=1}^{n} \bar{T}_{i} \quad \bar{T}_{i} \geq 10
$$

where $\bar{T}_{i}$ is the average temperature on Day $i, n$ is equal to 365 , and the calculation begins with the second day $>10^{\circ} \mathrm{C}$. If $\bar{T}_{i}<10$, then $\bar{T}_{i}=0$. That is, all the days with mean air temperatures $>10^{\circ} \mathrm{C}$ were considered for calculation.

We averaged meteorological data during the same 3 periods considered in the land-use dataset (the late 1980s, the mid-1990s and 2000). That is, we averaged meteorological data for $5 \mathrm{yr}$ for the 3 time periods. AAT10 values in the late 1980s, mid-1990s and 2000 were calculated with means from 1986-1990, 19931997 and 1998-2002 data, respectively. 


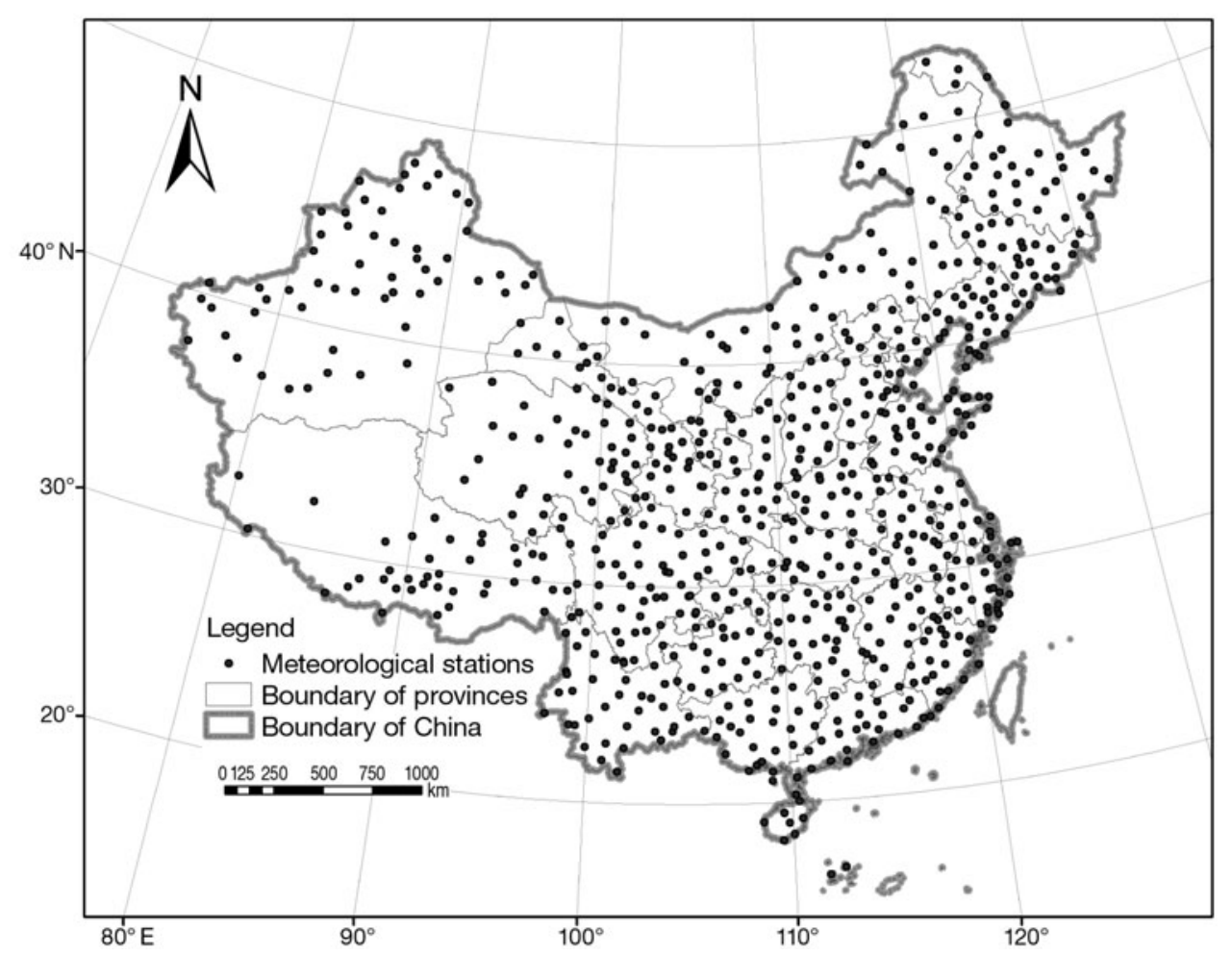

Fig. 1. Locations of 752 meteorological stations in China

\subsection{Methods}

\subsubsection{Designation of ATZs}

Dividing regions into ATZs is an effective method to examine the broader picture and smooth out the 'noise' of accumulated temperature. AAT10 is an important parameter in both agricultural climatic and physical geographic regionalization. Past spatial distributions of accumulated temperature can be found in various regionalization studies, such as those from the 1980s (Qiu \& Lu 1980, Qiu 1983, 1986). Studies of geographical regionalization methodologies have improved in recent years (Zheng et al. 2008). However, because trends of climate warming are complex and acute, previous regionalization studies have, thus for, not been able to precisely describe changes in the thermal conditions of farmland. ATZs must be regularly monitored to effectively indicate the changes in thermal conditions. In the present study, we used the classical criteria from traditional regionalization attempts to designate the ATZs (Table 1) for the 3 periods.

\subsubsection{Spatial statistical analysis}

We assessed the spatio-temporal thermal change characteristics of cultivated land on a macro-scale by (1) calculating the area of each ATZ in the 3 periods and (2) the area of cultivated land in each ATZ; (3) identifying the spatial distribution of transfer regions (i.e. regions where the ATZ is changing from

Table 1. Criteria of accumulated temperature zones (ATZs) and corresponding cropping systems, from the State Council Information Office of the People's Republic of China; revised by B. J. Qiu and B. W. Huang during the agricultural regionalization (according to physical conditions) of China in the 1980s (Tibetan Plateau is not included). AAT10: annual accumulated temperature $>10^{\circ} \mathrm{C}$

\begin{tabular}{|lccc|}
\hline ATZ & AAT10 $\left({ }^{\circ} \mathrm{C}\right)$ & Cropping system & Crop varieties \\
\hline Sugar cane & $>8000$ & 3 crops per year for rice & Rice, sugarcane, rubber \\
Rice & $4500-8000$ & 2 or 3 crops per year & Rice, winter wheat, cotton \\
Winter wheat & $3400-4500$ & 1 crop per year or 3 crops in 2 years & Winter wheat, cotton, corn, cotton, peanut \\
Spring wheat & $1600-3400$ & 1 crop per year & Spring wheat, corn, flax, soybean \\
Potato & $<1600$ & 1 crop per year & Spring wheat, potato \\
\hline
\end{tabular}



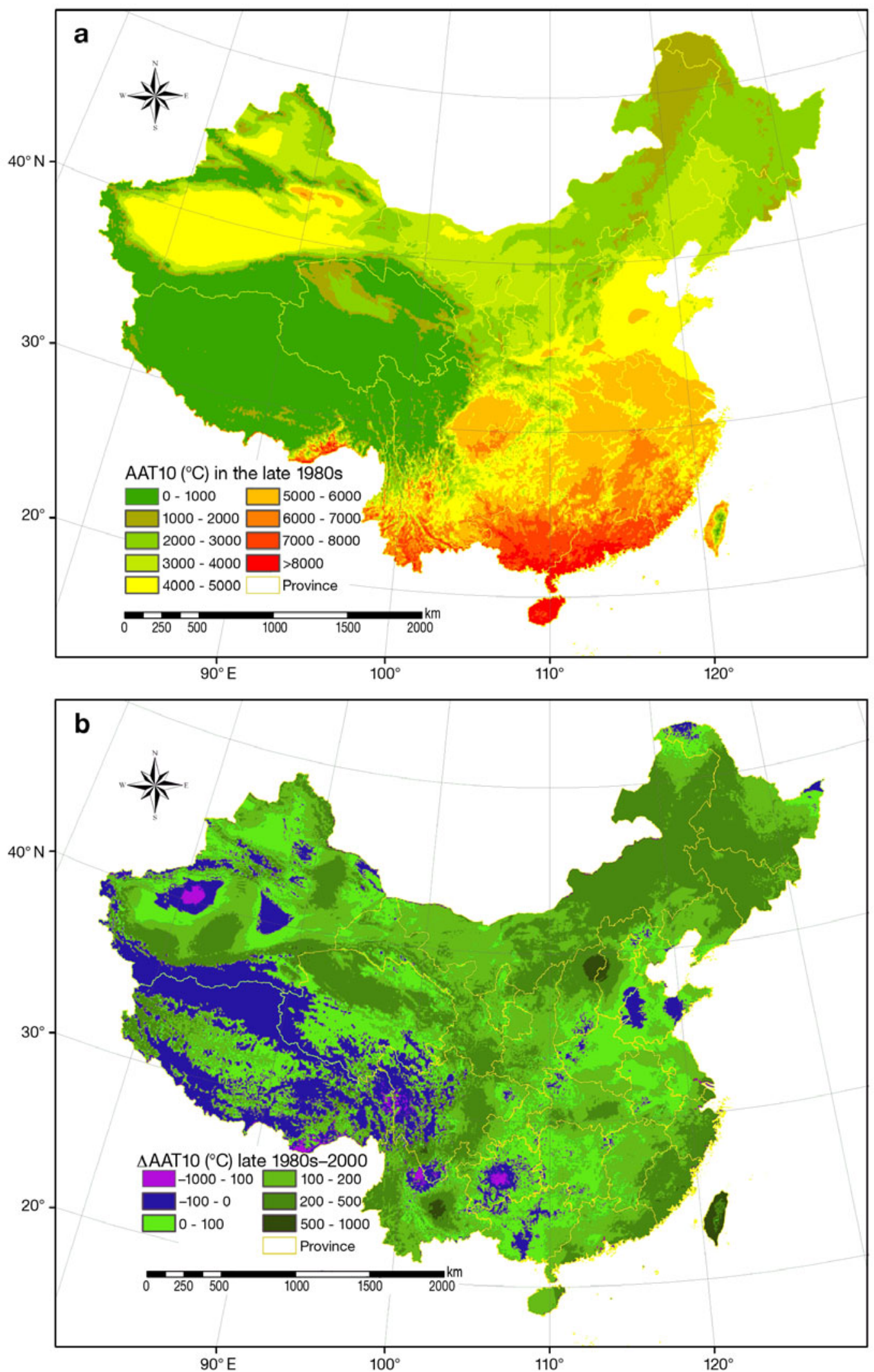

Fig. 2. (a) Spatial distribution of AAT10 (annual accumulated temperatures $>10^{\circ} \mathrm{C}$ ) in the late 1980 s (reference values) and (b) changes in AAT10 values from the late 1980s to 2000 
one AAT10 scale to another) in each ATZ by overlaying the 3 periods of data; and (4) determining the change in cultivated land area in the transfer regions.

\section{RESULTS}

\subsection{Spatio-temporal changes in AAT10}

\subsubsection{Spatial changes in AAT10}

While previous studies have shown that AAT10 of nearly all regions of the country first increased and then decreased between the 1930s and 1980s (Wang \& Wang 1985), we found that AAT10 increased slightly from the late 1980s to the mid-1990s in most parts of China. This pattern was seen in northeast China (principally eastern Inner Mongolia and most parts of Heilongjiang, Liaoning and Jilin Provinces), in the Huaihe River Basin (including Jiangsu and Anhui Provinces and other regions) and along the northern fringe of the Tianshan Mountains (including the northern Xinjiang Autonomous Region). However, AAT10 declined in some regions, including the western Inner Mongolia Autonomous Region, parts of Xinjiang and some regions south to the Yangtze River. Changes in AAT10 were significant during the second period from the mid-1990s to 2000 and AAT10 increased remarkably in most regions of China; by over $200^{\circ} \mathrm{C}$ in most parts of Inner Mongolia, southeastern coastal regions and south of the Tarim Basin.

Accumulated temperature increased in nearly all of China from the late 1980s to 2000. We found hotpots with clear AAT10 increases of $>100^{\circ} \mathrm{C}$ (Fig. 2b). The most significant regions of warming included the eastern part of Inner Mongolia, most parts of northeastern China, the Taihang Mountains (the northern part of the Huang-Huai-Hai Plain), southeastern coastal areas, Taiwan and the northern and eastern edges of the Qinghai-Tibet Plateau region. In some regions, AAT10 decreased, including a part of the Shandong Peninsula, the central part of the Huang-Huai-Hai Plain and a small area in the Tarim Basin.

\subsubsection{Designation of ATZs and area changes}

The distribution of AAT10 depended largely on latitude and altitude (Fig. 2a). The spatial structure of ATZs was steady on the whole, while partial changes occurred at the edges of ATZs. Accumulated temperature changes were analyzed by calculating the areas of ATZs in different periods since the late 1980s. Results showed that AAT10 increased on the whole, and the transfer from spring wheat ATZ to winter wheat ATZ was the most pronounced (Table 2, Figs. 3a,c \& 4).
(1) The area percentage of spring wheat ATZ fell to $26.53 \%$ in 2000 from $28.70 \%$ in the late 1980 s, and the total area of spring wheat ATZ decreased.

(2) The area percentage of winter wheat ATZ increased significantly from $13.69 \%$ in the late 1980 s to $15.37 \%$ in 2000 , with a persistent increasing trend in the 3 periods.

(3) The area percentage of potato ATZ declined slightly from $28.28 \%$ in the late 1980 s to $27.63 \%$ in 2000 .

(4) The area percentages of rice ATZ and sugar cane ATZ increased slightly by 0.81 and $0.32 \%$, respectively, from the late 1980 s to 2000 .

These results indicate that the thermal conditions improved on the whole; large areas converted from lower AAT10 to higher AAT10.

\subsubsection{Transfer of ATZs}

The above analysis indicated trends in thermal conditions on the whole, but it is important to understand distinct changes in thermal conditions, such as finer scale trends and the directions of trends. Transfer metrics of ATZ change from the late 1980 s to 2000 reflect the directions of conversion of thermal conditions more clearly (Table 3). The most pronounced conversion occurred from spring wheat ATZ to winter wheat ATZ, with a transfer area of $3.16 \times 10^{5} \mathrm{~km}^{2}$. Transfer areas from winter wheat ATZ to rice ATZ were also large, reaching $1.64 \times 10^{5} \mathrm{~km}^{2}$. Transfer areas from potato ATZ to spring wheat ATZ reached a total of $1.22 \times 10^{5} \mathrm{~km}^{2}$. In other words, ATZs moved northward, and the dominant trend indicated rising temperatures.

From the transfer matrix (Table 3), we determined the directions of ATZ change. Spatial analysis was used to ascertain the changes in thermal conditions based on spatial characteristics. Transfer regions were extracted through overlay analysis of ATZs during the late 1980s and 2000. With 5 zones, 20 transitions were possible; however, the 3 most common transitions described $>70.28 \%$ of all changes. The main transfer regions were chosen with large area changes to simplify the results (Fig. 4). The occurrence of spatial variation was clear. It is, thus, more effective to spatially

Table 2. Area percentages of ATZs for all of China during the 3 study periods

\begin{tabular}{|c|c|c|c|c|}
\hline \multirow[t]{2}{*}{ ATZ } & \multicolumn{3}{|c|}{ Area percentage of ATZs } & \multirow[t]{2}{*}{ Trend } \\
\hline & Late $1980 \mathrm{~s}$ & Mid-1990s & 2000 & \\
\hline Potato & 28.28 & 27.77 & 27.63 & $\downarrow$ \\
\hline Spring wheat & 28.70 & 28.34 & 26.53 & $\downarrow$ \\
\hline Winter wheat & 13.69 & 14.98 & 15.37 & $\uparrow$ \\
\hline Rice & 28.10 & 27.71 & 28.91 & $\uparrow$ \\
\hline Sugar cane & 1.24 & 1.20 & 1.56 & $\uparrow$ \\
\hline
\end{tabular}



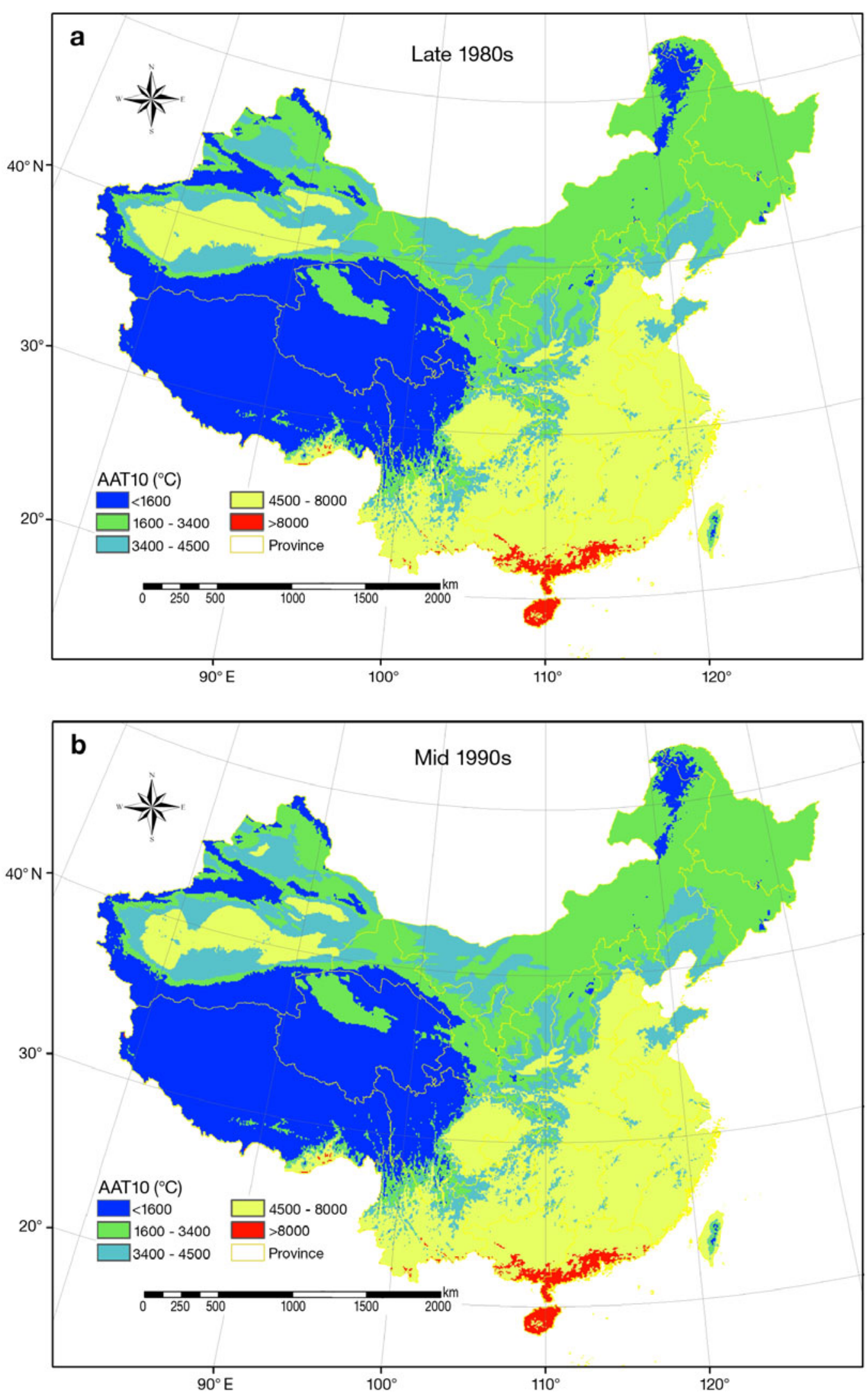

Fig. 3. ATZs (accumulated temperature zones) for the 3 periods: (a) late 1980s, (b) mid-1990s and (c) 2000 


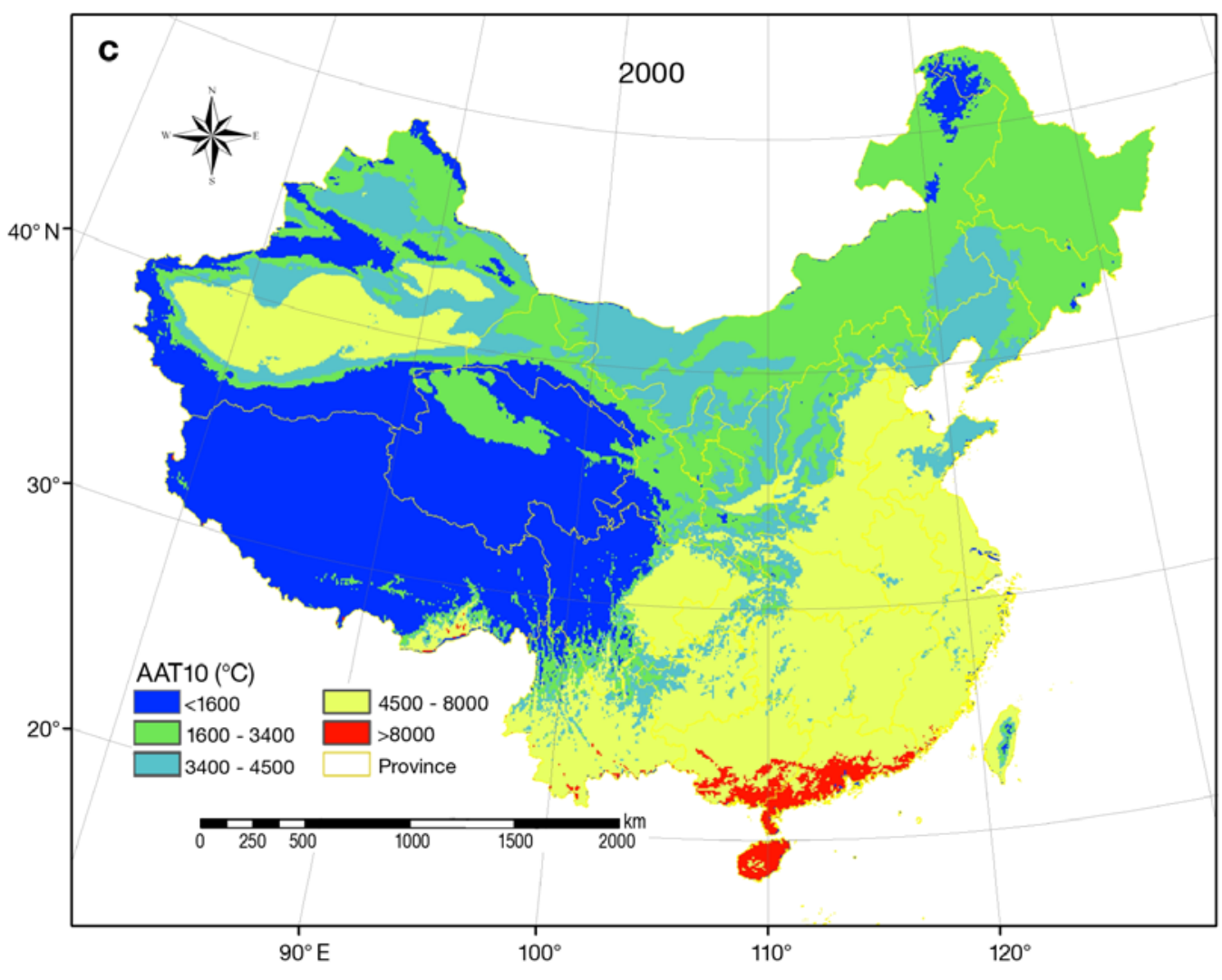

Fig. 3. (continued)

Table 3. Metrics of spatial transfer areas for different ATZs from the late 1980s to $2000\left(\mathrm{~km}^{2}\right)$. Bold: key transfer areas

\begin{tabular}{|c|c|c|c|c|c|c|c|}
\hline & ATZ & Potato & Spring wheat & Winter wheat & Rice & Sugar cane & Total \\
\hline \multirow{6}{*}{ 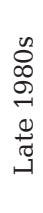 } & Potato & 2595227 & 122363 & 0 & 0 & 0 & 2680983 \\
\hline & Spring wheat & 22271 & 2386338 & 315892 & 512 & 0 & 2725013 \\
\hline & Winter wheat & 6400 & 4096 & 1119956 & 164090 & 0 & 1294541 \\
\hline & Rice & 0 & 0 & 25343 & 2580635 & 38143 & 2680727 \\
\hline & Sugar cane & 0 & 0 & 0 & 1536 & 109820 & 111356 \\
\hline & Total & 2623897 & 2512797 & 1461191 & 2746772 & 147962 & \\
\hline
\end{tabular}

identify areas of ATZ conversion than to assess changes in absolute AAT10 values (Fig. 2b).

3.1.3.1. Transfer from spring wheat ATZ to winter wheat ATZ. The area of spring wheat ATZ that transferred to winter wheat ATZ was the largest of all ATZ transfer areas. The most significant transfer region occurred in northeastern China, especially at the border of the western Jilin and Liaoning Provinces and the eastern Inner Mongolia Autonomous Region (Fig. 4, marked in blue rectangle). In addition, the boundaries of 2 ATZs moved northward $>400 \mathrm{~km}$. According to the thermal demand of crops, cropping systems in the region could move from 1 crop per year to 3 crops in 2 years. Lin et al. (2006) also found that the boundary of winter wheat has moved northward with improved thermal conditions.

The second major spring wheat ATZ to winter wheat ATZ transfer region was located in the Hetao region, but the warming trend in the region was not persistent. A third region was located in several scattered areas in Ningxia and Gansu Provinces and the Inner Mongolia Autonomous Region.

There was marked warming in North China with accompanying improvement in land suitability and cropping conditions. The boundary for growing winter wheat gradually moved northward from the late 1980s to 2000. These findings are consistent with existing research results (Xiao et al. 2007). 


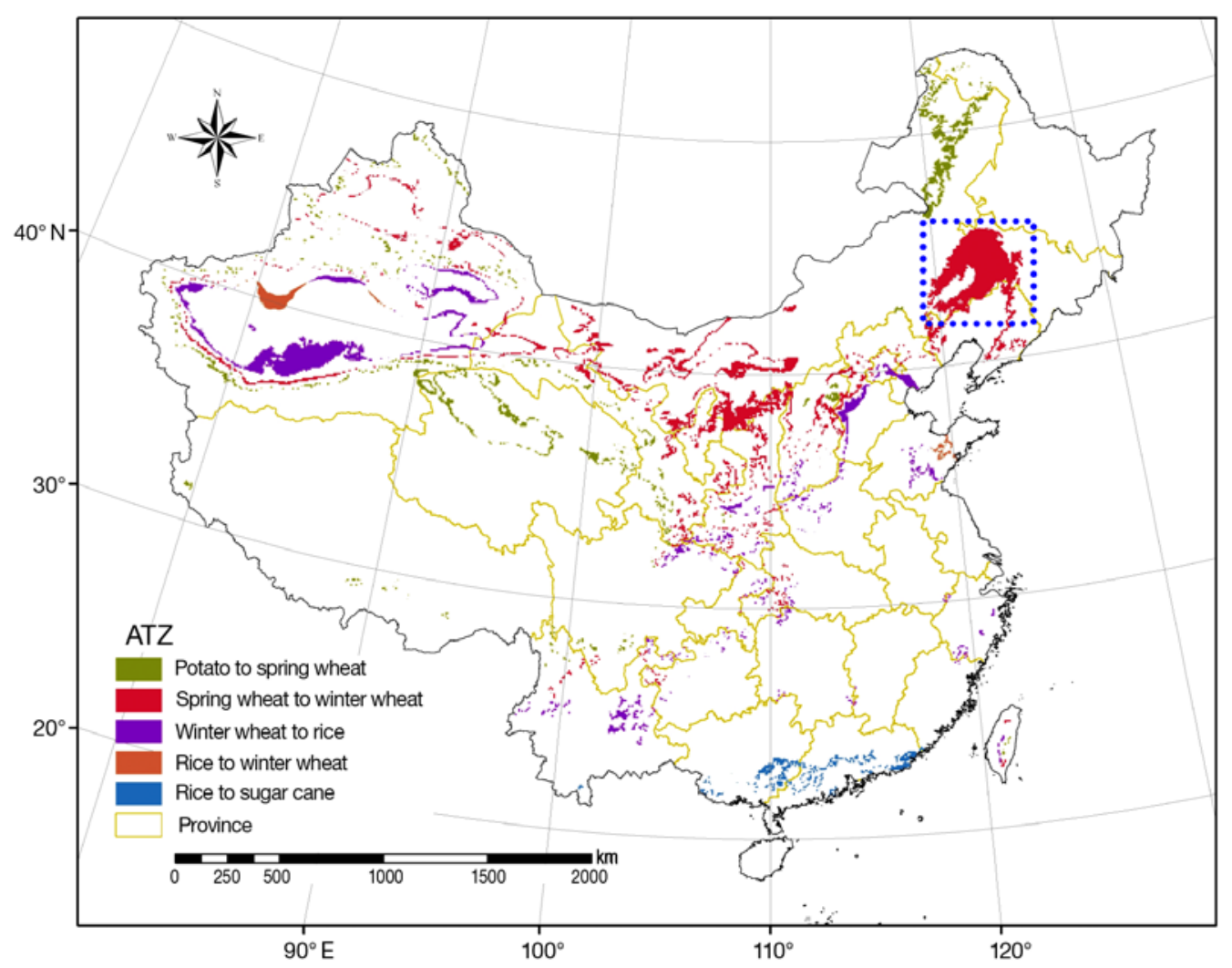

Fig. 4. Main transfer regions of ATZs from the late 1980s to 2000. The area bounded by the blue dotted rectangle is shown in Fig. 5

3.1.3.2. Transfer from winter wheat ATZ to rice ATZ and from potato ATZ to spring wheat ATZ. The southern margin of the Tarim Basin shifted from winter wheat ATZ to rice ATZ, while the northern margin of the Tarim Basin shifted in the opposite direction, from rice ATZ to winter wheat ATZ. Cropping systems in the region have changed little due to water constraints. In the northern region of Inner Mongolia, the AAT10 changed from $<1600^{\circ} \mathrm{C}$ to between 1600 and $3400^{\circ} \mathrm{C}$.

\subsection{Cultivated land changes in ATZ transfer regions}

\subsubsection{Areas of cultivated land}

We studied changes in the thermal conditions of cultivated land from the late 1980 s to 2000 , based on statistics of cultivated land in different ATZs. The percentage area of cultivated land in the spring wheat ATZ decreased from $28.02 \%$ in the late 1980 s to $25.51 \%$ in 2000. Meanwhile, the percentage area of cultivated land in the winter wheat ATZ increased from $15.09 \%$ in the late 1980 s to $17.58 \%$ in 2000 . Because the total area of cultivated land in China has increased, the areas of cultivated land under higher AAT10 values have increased more than they would have if the area of cultivated land had remained the same.

\subsubsection{Changes in cultivated land}

Table 4 illustrates cropland area in ATZ transfer regions. The largest cultivated land transfer, of $>5000 \mathrm{~km}^{2}$, was from spring wheat ATZ to winter wheat ATZ (Table 5). The spatial distribution of typical land transfer is shown in Fig. 5. Cultivated land expanded northward with improving thermal conditions, which was consistent with existing studies that had indicated that the gravimetric center of cultivated land had moved northward (Gao \& Liu 2006, Lin et al. 2006). Therefore, we found that cultivated land areas increased in the regions, with increasing AAT10, decreased with decreasing AAT10, and that a relationship exists between changes in cultivated land and changes in thermal conditions.

\section{DISCUSSION}

\subsection{Relationship between accumulated temperature changes and cultivated land use}

Several studies have investigated effects of landuse/land-cover change on climate (Li et al. 2006, Mahmood et al. 2006, Pielke 2005), but more studies are needed to address the effects of climate change on 
Table 4. Area $\left(\mathrm{km}^{2}\right)$ of cultivated land in different ATZs in the 3 study periods and pecentage of national total cultivated land area

\begin{tabular}{|c|c|c|c|c|c|c|}
\hline \multirow{2}{*}{ ATZ } & \multicolumn{2}{|c|}{ L Late $1980 \mathrm{~s}$} & \multicolumn{2}{|c|}{${ }_{-}$Mid-1990s } & \multicolumn{2}{|c|}{$2000-$} \\
\hline & Area $\left(\mathrm{km}^{2}\right)$ & Percentage & Area $\left(\mathrm{km}^{2}\right)$ & Percentage & Area $\left(\mathrm{km}^{2}\right)$ & Percentage \\
\hline Potato & 20280.50 & 1.15 & 16833.30 & 0.96 & 25839.40 & 1.44 \\
\hline Spring wheat & 495109.00 & 28.02 & 491665.00 & 28.07 & 457949.00 & 25.51 \\
\hline Winter wheat & 266701.00 & 15.09 & 285223.00 & 16.29 & 315587.00 & 17.58 \\
\hline Rice & 943251.00 & 53.39 & 921834.00 & 52.64 & 945931.00 & 52.68 \\
\hline Sugar cane & 41491.40 & 2.35 & 35768.10 & 2.04 & 50195.70 & 2.80 \\
\hline
\end{tabular}

Table 5. Main changes in cultivated land area $\left(\mathrm{km}^{2}\right)$ in transfer regions of ATZs from the late 1980s to 2000

\begin{tabular}{|lc|}
\hline Transition of ATZs & $\begin{array}{c}\text { Change in cultivated } \\
\text { land area }\left(\mathrm{km}^{2}\right)\end{array}$ \\
\hline Potato to spring wheat & 270.31 \\
Spring wheat to winter wheat & 5229.21 \\
Winter wheat to rice & -313.38 \\
Rice to winter wheat & 72.12 \\
Rice to sugar cane & -180.04 \\
\hline
\end{tabular}

land use, especially on agricultural land use and land suitability (Tao et al. 2003, Yokozawa et al. 2004, Mahmood et al. 2006). We found that the area of cultivated land increased where AAT10 increased (Fig. 6a,b, Table 5) and the suitability of land to be cultivated also increased with climate warming in most regions of China. For example, a large area was converted from spring wheat ATZ to winter wheat ATZ, thereby improving suitability for additional cropping. Because of agroecological environmental improvement, people

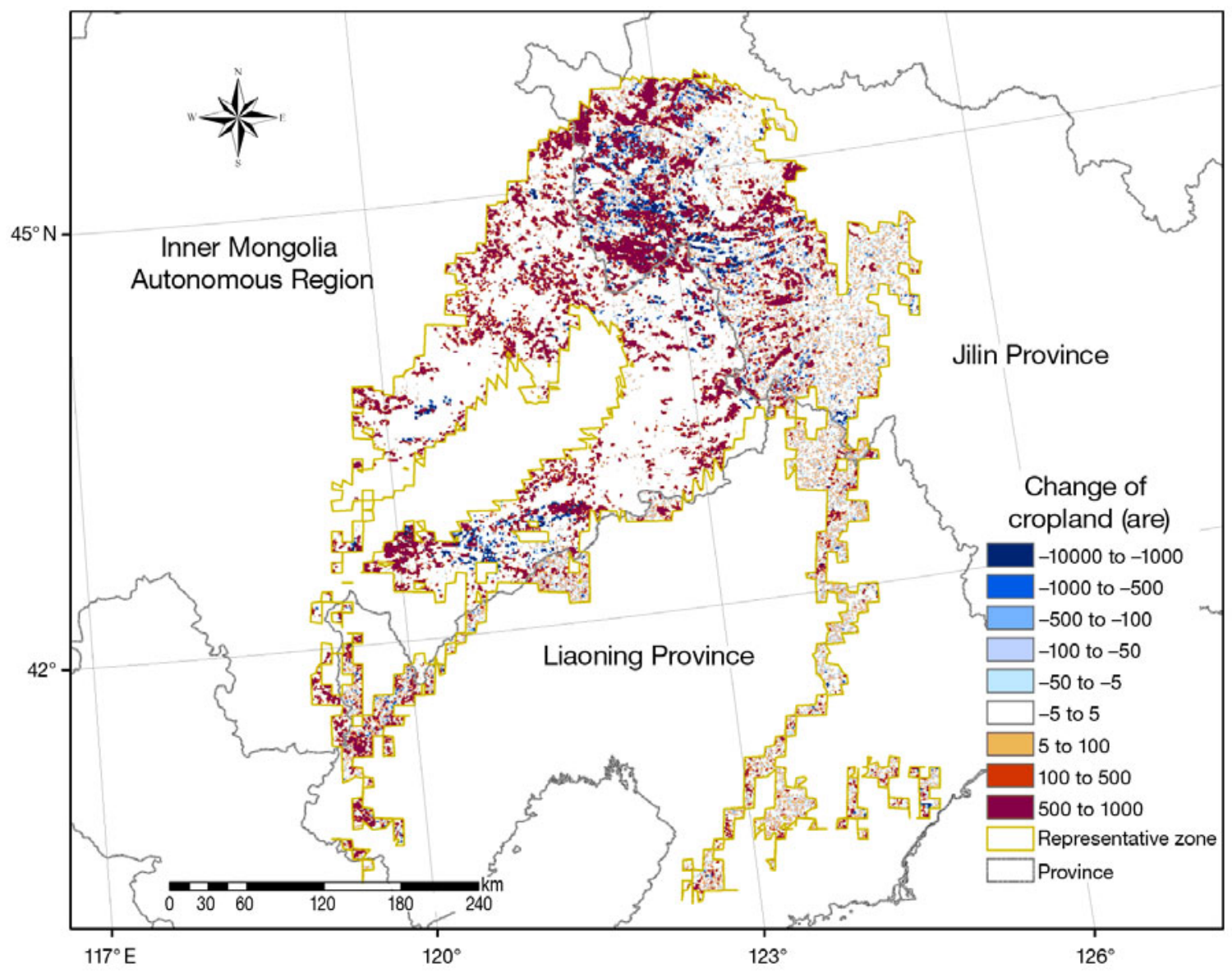

Fig. 5. Distribution of changes in cultivated land in transfer areas from spring wheat ATZ to winter wheat ATZ from the late 1980s to 2000. This region is an enlargement of the area in the blue rectangle in Fig. 4 
have cultivated more land, including land with low cropping indices, to produce more food and income. This practice has revealed the impacts of climate warming on agricultural land use to some extent. In addition, expanding crop areas have been driven by a series of factors besides the increase in accumulated temperature, e.g. the improvement of cultivars and, especially, water availability (Tao et al. 2003). Furthermore, food demands in China have increased as a result of the increasing population and more land has been reclaimed to meet these higher food demands (Yu \& Lu 2006); agriculture technology, such as information technology, machinery and irrigation, has provided the means to reclaim more arable land (Cox 2002). Some researchers point out that the adaptation options and potentials of both farmers and species were associated with different socio-economic capacities and policy intervention (Berry et al. 2006). Landuse changes occurred as a result of interactions between climate change and human activities.

The rate of change of cultivated land area from the late 1980s to the mid-1990s was slower than that in the later period because of a lag between changing climate and peoples' responses to a changing climate
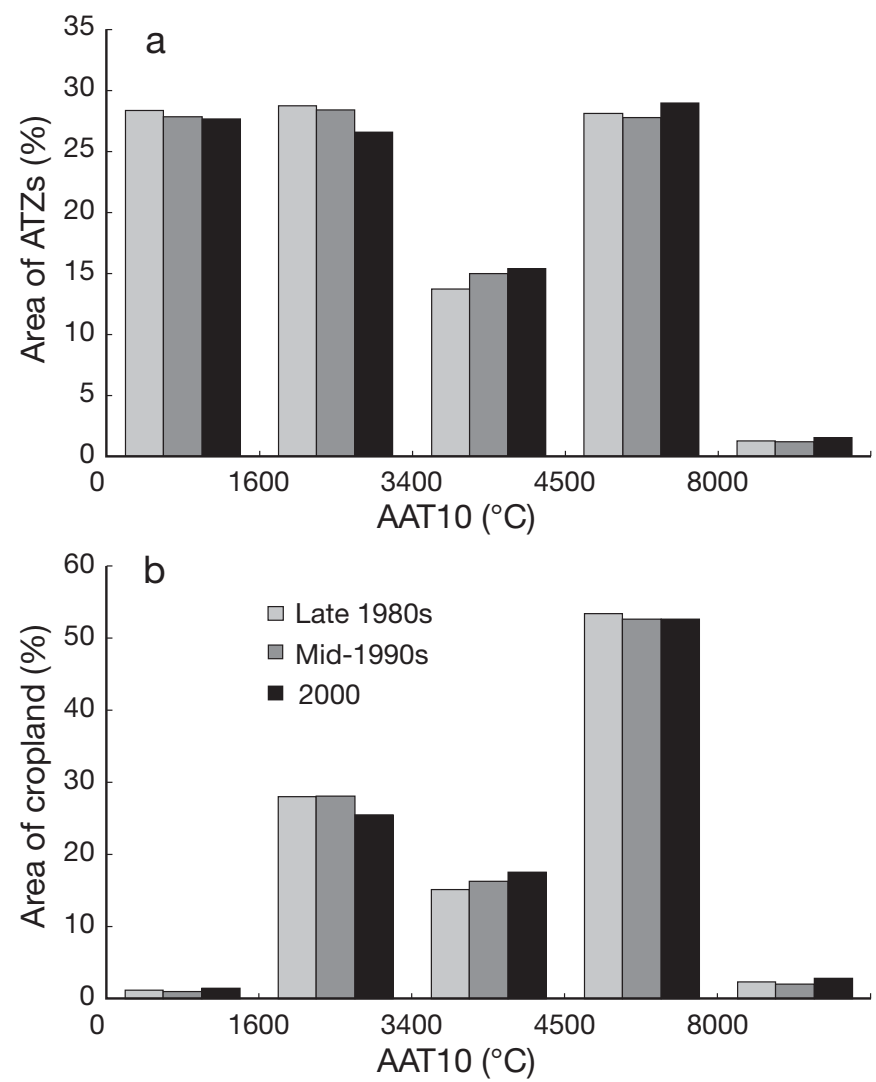

Fig. 6. (a) Area percentage of ATZs for AAT10 scales and different time periods. (b) Area percentage of cultivated land for different AAT10 scales and different time periods
(Table 4). However, changes in cultivated land area from the mid-1990s to 2000 were more significant than those in the previous period (Fig. 6b). This indicates that the extent of accumulated temperature changes influenced the quantity of changing cultivated land.

\subsection{Effects of accumulated temperature changes on cropping systems}

Changing thermal conditions have caused variation in the cropping index, which is defined as the number of crops grown per year in a given area of land. As a result of climate warming on a national scale, it is feasible for the cropping index to improve in some regions. To acquire higher yields of food and income, people have improved the cropping index in regions that had previously been difficult to crop and also in some areas where the index was low. According to the thermal accumulation demand (measured by AAT10) of crop farming (Table 1), cropping indices have improved in many regions since the 1980s (Yan et al. 2005, Li et al. 2008). This suggests that climate change has affected the thermal conditions of cultivated land and cropping systems (Feng \& Hu 2004, Miller et al. 2005, Cleland et al. 2007). AAT10 can quantify the thermal demand of crops; expected increases in the AAT10 can cause a reduction in the length of the growing period of determinate crops and shorten the duration of the crop cycle. This makes it possible for crops to acquire higher accumulated temperatures in less time and for the cropping index to increase.

ATZs play a significant role in regulating cropping. For example, differing ATZs in Heilongjiang Province provide an important guide for cropping, and farmers choose crop breeds and decide on sowing dates strictly according to the designation of ATZs (Yu et al. 1997). The spatial distribution of ATZs shown in the present study may be able to assist in decision-making regarding the crop planting distribution.

\subsection{Possible effects of accumulated temperature increases on future agriculture}

Substantial work has been done on the possible effects of climate change, especially temperature change; for example, Brown et al. (2008) asserted that climate change is acting to enhance the land-use potential in Scotland. If warming in China continues, cropping indices will continue to improve, but other unpredictable climate events may occur. The demand for cultivated land will decrease with improved cropping indices and efficient food production. However, accumulated temperature rises and a warming climate 
will expand the range of many agricultural pests and increase pest populations (Schmidhuber \& Tubiello 2007), as well as increasing evapotranspiration and the demand for water and pesticides as the area of cultivated land increases (Tao et al. 2003). In addition, spatial extension of arable land may reduce the integrity of pristine natural environment by anthropogenic disturbances.

\subsection{Uncertainty analysis}

AAT10 is a key agroecological parameter that indicates thermal demand for crop growth. However, in addition to accumulated temperature, other factors, such as precipitation and extreme weather events, affect crop growth (Riha et al. 1996, Challinor et al. 2005). Moisture and other natural conditions differ among regions (Tao et al. 2003), and climate warming may lead to increased irrigation requirements (Tao et al. 2003), which could cause crop failure during drought conditions in some regions (Tao et al. 2003, Liu \& Lin 2004). The frequency of extreme agrometeorological events substantially influences crops in some regions and may create a risk for cropland suitability (Tao et al. 2003, Yokozawa et al. 2004). For example, extremely low minimum temperatures often restrict the growth of crops in northwestern China (Zheng et al. 2008), rain-fed cropland on the North China Plain could face the challenge of frequent droughts associated with climate change and variability (Tao et al. 2003, Yokozawa et al. 2004). In addition, soil degradation is another important problem (Tao et al. 2005). Further studies are needed to explore the relationship between water needs and thermal conditions.

In addition, the Qinghai-Tibet Plateau has a special geographical and agroecological environment. In the present study, insufficient specific analyses were performed on the Qinghai-Tibet Plateau. However, because the Qinghai-Tibet Plateau supports limited agricultural production, results from additional analyses of this region would not likely influence the conclusions of our paper. Other possible uncertainties are connected with the data. Land-use data were derived from LANDSAT images with a resolution of about $30 \mathrm{~m}$; subsequently, information on cultivated land was extracted and converted into $1 \mathrm{~km} \times 1 \mathrm{~km}$ grids. While the climate data were derived from the interpolation of 752 stations, the spatial distribution was uneven. Although topography was considered in the interpolation, it was difficult to guarantee perfect consistency with the land-use data. Furthermore, the scale effect and consistency of the 2 datasets need more study in the future.

\section{CONCLUSIONS}

In the present study the spatio-temporal changes of AAT10 based on meteorological data were examined. By analyzing ATZs and cultivated land, a relationship between cultivated land and thermal conditions was proposed, and the potential effects of accumulated temperature on cultivated land and farming systems were assessed. The main conclusions are as follows:

(1) Since the late 1980s, AAT10 has noticeably risen in most of China. It is most pronounced in the araes converted from spring wheat ATZ to winter wheat ATZ $\left(3.16 \times 10^{5} \mathrm{~km}^{2}\right)$; winter wheat ATZ to rice ATZ $(1.64 \times$ $\left.10^{5} \mathrm{~km}^{2}\right)$; and potato ATZ to spring wheat ATZ $(1.22 \times$ $\left.10^{5} \mathrm{~km}^{2}\right)$.

(2) Changes in accumulated temperature affected cultivated land use. The area of cultivated land increased in accordance with rising AAT10. Changes in cultivated land area from spring wheat ATZ to winter wheat ATZ exceeded $5000 \mathrm{~km}^{2}$.

(3) Cropping indices have changed because of improved thermal conditions since the late 1980s. For example, cropping indices changed from a single crop per year to 3 crops in 2 years in the eastern Inner Mongolia Autonomous Region and the Hetao region. Farming systems also changed, and the growth boundary of winter wheat moved northward.

Acknowledgements. The present study was supported by the National Key Programme for Developing Basic Science (Project Number 2009CB421105) and the Knowledge Innovation Program of the Chinese Academy of Sciences (Grant No. KSCX1YW-09-01). F.T. acknowledges the support of the 'Hundred Talents' Program of the Chinese Academy of Sciences. We thank Dr. W. J. Shi for her assistance in grammar, and we thank 4 anonymous reviewers for their very valuable comments.

\section{LITERATURE CITED}

Bai QF, Huo Z, Li S, Du H, He N, Jiang Y (2008) Comparison of accumulated temperature above $10^{\circ} \mathrm{C}$ before and after the year 1978 in China. Chin J Appl Ecol 19:1810-1816 (in Chinese with English abstract)

Berry PM, Rounsevell MDA, Harrison PA, Audsley E (2006) Assessing the vulnerability of agricultural land use and species to climate change and the role of policy in facilitating adaptation. Environ Sci Policy 9:189-204

Brown I, Towers W, Rivington M, Black HIJ (2008) Influence of climate change on agricultural land-use potential: adapting and updating the land capability system for Scotland. Clim Res 37:43-57

Challinor AJ, Wheeler TR, Craufurd PQ, Slingo JM (2005) Simulation of the impact of high temperature stress on annual crop yields. Agric For Meteorol 135:180-189

Cleland EE, Chuine I, Menzel A, Mooney HA, Schwartz MD (2007) Shifting plant phenology in response to global change. Trends Ecol Evol 22:357-365

Cox S (2002) Information technology: the global key to precision agriculture and sustainability. Comput Electron Agric 36:93-111 
Ding Y, Ren G, Shi G, Gong P and others (2006) National assessment report of climate change (I): climate change in China and its future trend. Adv Clim Change Res 2:3-8

Ding Y, Ren G, Zhao Z, Xu Y, Luo Y, Li Q, Zhang J (2007) Detection, causes and projection of climate change over China: an overview of recent progress. Adv Atmos Sci 24: 954-971

Feng S, Hu Q (2004) Changes in agro-meteorological indicators in the contiguous United States: 1951-2000. Theor Appl Climatol 78:247-264

Gao Z, Liu J (2006) The LUCC responses to climatic changes in China from 1980 to 2000. Acta Geogr Sin 61:865-872 (in Chinese with English abstract)

Hutchinson MF (2002) ANUspline, Version 4.2, user guide

Li Q, Ding Y, Dong W (2006) A numerical simulation on impact of historical land-use changes on regional climate in China since 1700. Acta Meteorol Sin 64:257-270

Li J, Gao P, Chen YC, Chen H, Yang TM (2008) Relationships between farming system and effective accumulated temperature in East China. Chin J Ecol 27:361-368 (in Chinese with English abstract)

Lin E, Xu Y, Jiang J, Li Y, Yang X and others (2006) National assessment report of climate change (II): climate change impacts and adaptation. Adv Clim Chang Res 2:51-56

Liu J (1996) Macro-scale survey and dynamic study of natural resources and environment of China by remote sensing. China Science and Technology Press, Beijing (in Chinese)

Liu X, Lin E (2004) Impact of climate change on water requirement of main crops in North China. J Hydraul Eng 35:77-82 (in Chinese with English abstract)

Liu J, Liu M, Zhuang D, Zhang Z, Deng X (2003) Study on spatial pattern of land-use change in China during 1995-2000. Sci China Ser D Earth Sci 46:373-384

Liu H, Li XB, Fischer G, Sun LX (2004) Study on the impacts of climate change on China's agriculture. Clim Change 65: 125-148

Liu J, Liu M, Tian H, Zhuang DF and others (2005) Spatial and temporal patterns of China's cropland during 1990-2000: an analysis based on Landsat TM data. Remote Sens Environ 98:442-456

Lobell DB, Asner GP (2003) Climate and management contributions to recent trends in US agricultural yields. Science 299:1032

Lobell DB, Burke MB, Tebaldi C, Mastrandrea MD, Falcon WP, Naylor RL (2008) Prioritizing climate change adaptation needs for food security in 2030. Science 319:607-610

Mahmood R, Pielke RA, Hubbard KG (2006) Land use/land cover change and its impacts on climate. Global Planet Change 54:7

Miller P, Mitchell M, Lopez L (2005) Climate change: length of growing-season in the US Corn Belt, 1911-2000. Phys Geogr 26:85-98

Pielke RA Sr (2005) Land use and climate change. Science 310:1625-1626

Qin D, Ding Y, Su J, Ren J and others (2005) Assessment of climate and environment changes in China. I. Climate and environment changes in China and their projection. Adv Clim Change Res 1:4-9

Editorial responsibility: Tim Sparks, Girton, Cambridge, United Kingdom
Qiu B (1983) Further study on the regionalization of agroclimate of China. Acta Geogr Sin 38:154-162 (in Chinese with English abstract)

Qiu B (1986) A new discussion on the regionalization of agroclimate in China. Acta Geogr Sin 41:202-209 (in Chinese with English abstract)

Qiu B (1992) Some notes on the map of agricultural physical regionalization in China and its tables. J Henan Univ Nat Sci 22:69-73 (in Chinese with English abstract)

Qiu B, Lu Q (1980) A tentative regionalization of agroclimate of China. Acta Geogr Sin 35:116-125 (in Chinese with English abstract)

Riha SJ, Wilks DS, Simoens P (1996) Impact of temperature and precipitation variability on crop model predictions. Clim Change 32:293-311

Schmidhuber J, Tubiello FN (2007) Global food security under climate change. Proc Natl Acad Sci USA 104: 19703-19708

Tao F, Yokozawa M, Hayashi Y, Lin E (2003) Changes in agricultural water demands and soil moisture in China over the last half-century and their effects on agricultural production. Agric For Meteorol 118:251-261

> Tao F, Yokozawa M, Hayashi Y, Lin E (2005) A perspective on water resources in China: interactions between climate change and soil degradation. Clim Change 68:169-197

Tao F, Yokozawa M, Xu YL, Hayashi Y, Zhang Z (2006) Climate changes and trends in phenology and yields of field crops in China, 1981-2000. Agric For Meteorol 138:82-92

> Tao F, Yokozawa M, Liu J, Zhang Z (2008a) Climate-crop yield relationships at provincial scales in China and the impacts of recent climate trends. Clim Res 38:83-94

Tao F, Hayashi Y, Zhang Z, Sakamoto T, Yokozawa M (2008b) Global warming, rice production, and water use in China: developing a probabilistic assessment. Agric For Meteorol 148:94-110

Wang F, Wang S (1985) An analysis on the characteristics of accumulated temperature variation in China. Sci Geogr Sin 5:201-208 (in Chinese with English abstract)

Xiao G, Zhang Q, Wang J (2007) Impact of global climate change on agro-ecosystem: a review. Chin J Appl Ecol 18:1877-1885 (in Chinese with English abstract)

Yan H, Liu J, Cao M (2005) Remotely sensed multiple cropping index variations in China during 1981-2000. Acta Geogr Sin 60:559-566 (in Chinese with English abstract)

Yokozawa M, Tao F, Sakamoto T (2004) Risk analysis of cropland suitability in China under climate variability and change. Crop Environ Bioinformatics 1:264-271

> Yu B, Lu C (2006) Change of cultivated land and its implications on food security in China. Chin Geogr Sci 16: 299-305

Yu R, Shun M, Zhang L (1997) The re-division about the quantity of heat resources and the accumulated temperature zone of Heilongjiang Province. Nat Sci J Harbin Normal Univ 13:98-102 (in Chinese with English abstract)

Zheng D, Ou Y, Zhou CH (2008) Understanding of and thinking over geographical regionalization methodology. Acta Geogr Sin 63:563-573 (in Chinese with English abstract)

Submitted: March 24, 2009; Accepted: June 11, 2009

Proofs received from author(s): August 27, 2009 